\title{
EFFECT OF INTRAVENOUS LIDOCAINE, INTRAVENOUS ESMOLOL AND INTRAVENOUS CLONIDINE ON HAEMODYNAMIC RESPONSES TO LARYNGOSCOPY AND ORO-TRACHEAL INTUBATION IN NORMOTENSIVE PATIENTS: A DOUBLE BLINDED, COMPARITIVE STUDY
}

\author{
Savitha K.S ${ }^{1}$, Sampa Anupurba², Smita L. Almeida ${ }^{3}$
}

\section{HOW TO CITE THIS ARTICLE:}

Savitha K.S, Sampa Anupurba, Smita L. Almeida."Effect of Intravenous Lidocaine, Intravenous Esmolol and Intravenous Clonidine on Hemodynamic Responses to Laryngoscopy and Oro-Tracheal Intubation in Normotensive Patients: A Double Blinded, Comparative Study". Journal of Evolution of Medical and Dental Sciences 2014; Vol. 3, Issue 02, January 13; Page: 479-487, DOI:10.14260/jemds/2014/1853

BACKGROUND: The pressure response to laryngoscopy and endotracheal intubation is without sequel in healthy individuals. In patients with pre-existing diseases, may precipitate myocardial ischemia, arrhythmias, infarction and cerebral hemorrhage. In view of that, the objectives of our study was, to assess the hemodynamic variations to laryngoscopic intubation and to evaluate the comparative efficacy of I.V Lidocaine, I.V Esmolol and I.V Clonidine, in attenuating the sympathetic response to laryngoscopy and orotracheal intubation in normotensive patients. METHODS: In our double blind, randomized, clinical prospective study 105 Indian ethnicity patients of either sex requiring oral intubation, who met inclusion criteria, were considered. Randomly patients were stratified into three groups ( $n=35$ patients each) Group C, Group E and Group L to receive inj Clonidine $1.5 \mu \mathrm{g} / \mathrm{kg}$, inj Esmolol $1.5 \mathrm{mg} / \mathrm{kg}$ and inj Lidocaine $1.5 \mathrm{mg} / \mathrm{kg}$ respectively at $15 \mathrm{~min}, 3 \mathrm{~min}$ and 3 min prior to intubation as premedication. Two senior postgraduates who were not involved in patient care were responsible for blinding techniques. Data obtained were analyzed after decoding. Analysis of variance (ANOVA), Chi-square/Fisher Exact test has been used to find the significance of study parameters on categorical scale between the three groups. RESULTS: In our study there was strongly significant raise in heart rate (HR), systolic blood pressure (SBP), diastolic blood pressure (DBP) and mean arterial pressure (MAP) at one minute following intubation in all three groups (p $<0.001)$. HR reached base line at $4 \mathrm{~min}$ in group $\mathrm{E}$ which was statistically significant $(\mathrm{p}<0.001)$. In group C, SBP and DBP reached base line value in $2 \mathrm{~min}$ and $3 \mathrm{~min}$ Which is again statistically strongly significant ( $\mathrm{p}<0.001)$. CONCLUSION: Esmolol $1.5 \mathrm{mg} / \mathrm{kg} \mathrm{I.V,} 3 \mathrm{~min}$ prior to oro-tracheal intubation is a better drug of choice to control HR and Clonidine $1.5 \mu \mathrm{g} / \mathrm{kg} \mathrm{I.V}, 15 \mathrm{~min}$ prior to orotracheal intubation is preferred to attenuate hypertensive response to laryngoscopy and intubation in a normotensive patients.

KEY WORDS: Lidocaine, Esmolol, Clonidine, laryngoscopy, oro-tracheal intubation, hemodynamic response, normotensive patients.

INTRODUCTION: The pressure response to laryngoscopy and endotracheal intubation was recognized and documented as early as $1951 .{ }^{1}$ These responses are usually transitory, variable and without sequel in healthy individuals. ${ }^{1,2,3}$ In patients with pre-existing diseases (coronary artery disease, hypertension and cerebrovascular diseases) may precipitate myocardial ischemia, arrhythmias, infarction and cerebral hemorrhage. ${ }^{4,5}$ In these patients careful hemodynamic control during induction of anesthesia and intubation of trachea has to be considered. 
The hemodynamic response is mediated by the sympatho adrenal system. Vagus nerve carries the sensory impulse to the nucleus tractus solitarius initiating the reflex arc. The Nucleus tractus solitaries along with supramedullary area in pons and hypothalamus modulate carotid sinus baroreflex. It also projects to the spinal sympathetic out flow to the visceral efferent in heart, lungs and somatic efferent to pharynx and larynx. ${ }^{6}$

Laryngoscopy and intubation causes 40 to 50\% rise in SBP, 30\% rise in DBP and 20\% rise in HR.7 To attenuate the hemodynamic response various pharmacological agents have been used.

Narcotics seem to have constant and reliable effect, with possibilities of postoperative respiratory depression. Lidocaine is the drug, used most in clinical practice. Short acting betablockers with anti-arrhythmic, anti-hypertensive, anti-ischemic and bradycardic properties have been advocated. ${ }^{8}$ Vasodilators (nitroglycerin) are indicated in patients with coronary artery disease. ${ }^{9}$ Calcium channel blockers seem to be less effective. ${ }^{10}$ Studies have shown that Magnesium is also effective in preventing the pressure response. ${ }^{10}$ Alpha- 2 adrenergic agonist has shown to have properties that are of potential benefit in premedication. ${ }^{11,12}$ Not a single method or drug is effective in totally attenuating the hemodynamic response.

The objective of our study was to assess, the hemodynamic variations to laryngoscopic intubation and to evaluate the comparative efficacy of I.V Lidocaine, I.V Esmolol and I.V Clonidine, which acts at various levels of reflex arc, in attenuating the sympathetic response to laryngoscopy and orotracheal intubation in normotensive patients.

MATERIAL AND METHODS: The randomized, prospective, double blind, single centre study was undertaken at tertiary care hospital after obtaining hospital ethical committee approval and informed written consent from the patient. The study included 105 Indian ethnicity patients of either sex of ASA (American Society of Anesthesiologist) grade I, with airway assessment of Mallampatti grade 1 and 2, between the age group of 18-65 years, scheduled for elective surgeries under general anesthesia requiring oral intubation, done within 30 seconds of direct laryngoscopy using Macintosh blade. Patients were excluded if they refuse to participate, history of allergy to any drug and more than one attempt at intubation.

Randomization was done using computer generated number and stratified into three groups ( $\mathrm{n}=35$ patients each) Group C, Group E and Group L to receive inj Clonidine $1.5 \mu \mathrm{g} / \mathrm{kg}$, inj Esmolol 1.5 $\mathrm{mg} / \mathrm{kg}$ and inj Lidocaine $1.5 \mathrm{mg} / \mathrm{kg}$ respectively at $15 \mathrm{~min}, 3 \mathrm{~min}$ and $3 \mathrm{~min}$ prior to intubation as premedication. Two senior postgraduates who were not involved in patient care generated random sequence and they were sequentially numbered. Study drug was prepared in $20 \mathrm{ml}$ saline in a $20 \mathrm{cc}$ syringe and they were labeled with sequential number, for blinding purpose. Drug administration and parameters recording were done by anesthesiologist blinded to the study. Patients included in the study were also blinded to the study drug. Decoding was done for statistical analysis after the completion of the study.

On the day of surgery, confirming the pre-an aesthetic check-up, 30 minutes prior to induction patients were mobilized to the induction room. Monitors like non-invasive blood pressure, pulse oximetry and electro-cardiogram were connected and monitored continuously. Securing the I.V line all patients were started with maintenance fluid (ringer's lactate) and premedicated with injection midazolam $0.03 \mathrm{mg} / \mathrm{kg}$ I.V. with supplemental oxygen $4 \mathrm{~L} / \mathrm{min}$ through Hudson mask. 
Patients were shifted to the operation suite 20 minutes prior to induction. Supplemental oxygen was continued till pre-oxygenation with $100 \%$ oxygen. All patients received $20 \mathrm{ml}$ saline I.V. (with or without Clonidine) $15 \mathrm{~min}$ prior to induction. $3 \mathrm{~min}$ before induction patients were preoxygenated with $100 \%$ oxygen and $20 \mathrm{ml}$ saline (plain or with Esmolol or with Lidocaine) was administered I.V followed by Glycopyrolate $0.2 \mathrm{mg}$ and fentanyl $2 \mu \mathrm{g} / \mathrm{kg}$.

Patients were induced with inj propofol $1 \mathrm{mg} / \mathrm{kg}$ I.V over 30 seconds, ventilated and maintained with $40 \%$ oxygen in nitrous oxide and Isoflurane (1 MAC). Airway was secured, by consultant anesthesiologist with appropriate size endotracheal tube (ETT) following inj Atracurium $0.5 \mathrm{mg} / \mathrm{kg}$ I.V. ETT placement patients was confirmed and ventilation was aimed to achieve normocarbia. Analgesia was standardized with inj Diclofenac Sodium $75 \mathrm{mg}$ I.V and/or Morphine $0.01 \mathrm{mg} / \mathrm{kg}$. At the conclusion of the surgery residual neuromuscular blockade was reversed with inj Neostigmine $0.05 \mathrm{mg} / \mathrm{kg}$ and glycopyrrolate $6 \mu \mathrm{g} / \mathrm{kg}$. Patients were assessed clinically and extubated, establishing adequate tidal volume. HR, SBP, DBP and MAP recorded at base line, after induction and $0,1,2,3,4,6,8$, and $10 \mathrm{~min}$ following intubation were considered for statistical analysis.

In our study descriptive statistical analysis was carried out. Results on continuous measurements are presented on Mean \pm SD (Min-Max) and results on categorical measurements are presented in Number (\%). Significance is assessed at 5\% level of significance. Analysis of variance (ANOVA), Chi-square/Fisher Exact test has been used to find the significance of study parameters on categorical scale between the three groups. For analysis $p<0.10$ suggestive significance, $p \leq 0.05$ is moderately significant and $\mathrm{p} \leq 0.01$ is strongly significant

RESULTS: The demographic characteristics, age sex and weight are detailed in table 1. Statistically no differences were noted between the 3 groups. In our study there was strongly significant raise in HR, SBP, DBP and MAP at one minute following intubation in all three groups $(\mathrm{p}<0.001)($ Table $3-5)$. In group E, SBP and MAP reached base line at $3 \mathrm{~min}$, whereas HR and DBP took 4min, which was statistically significant ( $\mathrm{p}<0.001$ ) (Figure 1). Myocardial perfusion takes place during diastole. So drug which reduces DBP is always a better choice to minimize perioperative morbidity and mortality especially in high risk group of patients' e.g. coronary artery disease. In this concern comparatively clonidine is a better choice to control BP because it took 2 min for SBP and MAP to reach the base line value where as DBP took $3 \mathrm{~min}$. Which is again statistically strongly significant $(\mathrm{p}$ $<0.001$ ). HR reached base line values at $4 \mathrm{~min}$ in group $\mathrm{E}$ whereas in group L and C it took 8 and 10 min. From our observation esmolol is a better choice to control HR.

On comparative observation between the groups, our study reveals that, there is no statistical significant fall in HR in C-L comparison ( $\mathrm{p}$ 0.988) (Table 2). So clonidine and lignocaine are not better choice to reduce the HR in stressful situation. Fall in SBP, DBP and MAP in group E and C are statistically significant $(\mathrm{p}<0.001)$. But between the two groups, fall in the BP was not statistically significant ( $\mathrm{p}$ 0.699). Inference is, either of the drugs could be the choice to control BP (Figure 2).

DISCUSSION: During induction, direct laryngoscopy and endotracheal intubation, cardiacarrhythmia occurs in $90 \%$ of patients, due to sympatho adrenal response and afferent stimulation of vagus, which might prove harmful to the myocardium and may be fatal to the patient.7, 13 To circumvent these responses, our study was undertaken. 
Heart rate variation decreases with increasing age, is extreme in young patients and marked fluctuations are often seen in geriatric patients. ${ }^{14,15}$ Keeping it in view patients between 18-65 years were considered in our study.

Singh and Smith et al ${ }^{16}$ have concluded that, nasotracheal intubation causes significant pressure response but not direct laryngoscopy. Whereas Nandita S et al ${ }^{17}$ has highlighted direct laryngoscopy alone may produce most of the cardiovascular responses. Considering the later we included direct laryngoscopy and oro-tracheal intubation in our study.

Laryngoscopy has linear relation with presser response during first 48sec, with further prolongation has little effect. ${ }^{18}$ Keeping it as a guide we have limited laryngoscopy and intubation to less than 30sec. The criteria stated by Bachofen $M$ to prevent sympathetic response are met by our study drugs inj Lidocaine, inj Esmolol and inj Clonidine. ${ }^{19}$

To attenuate cardiovascular response, studies on oral clonidine ( $\alpha-2$ agonist) are done. ${ }^{20,21}$ But there are limited studies with I.V clonidine in comparison with other drugs to attenuate hemodynamic response. In view of that clonidine is one of our study drugs.

Ugur B at al has administered Esmolol $1.5 \mathrm{mg} / \mathrm{kg} 2 \mathrm{~min}$ before intubation to prevent hemodynamic responses to endotracheal intubation. Similarly we too have considered the same dose. But for blinding purpose we have administered 3 min prior to intubation.

Many studies are carried out with Lidocaine to attenuate cardiovascular responses to laryngoscopy and intubation with a recommended dose of $1.5-2 \mathrm{mg} / \mathrm{kg}$ I.V.14, 22, 23 In a study by Abou-Madi $\mathrm{M} \mathrm{N}$ et al have recommended the $I . V$ dose of Lidocaine $1.5 \mathrm{mg} / \mathrm{kg}$ to attenuate hemodynamic changes to intubation, administered 3 min prior to intubation. Similarly we have considered in our study.

In our study in Esmolol group, rise in HR occurred during intubation which reach baseline values after 4 min. This finding corroborates with the findings of Feng CK et al. ${ }^{24}$ In clonidine group, rise in HR was observed in our study during first 4 min after intubation which reached baseline values by 10 min. This matches with the findings of Adachi YU et al. ${ }^{25}$ In Lidocaine group;rise in HR was seen till $5 \mathrm{~min}$ after intubation which reach baseline values after $10 \mathrm{~min}$. This matches with the findings of Kobayashi TL et al. ${ }^{26}$ and Miller CD et al. ${ }^{27}$ Our observation has showed that a bolus dose of Esmolol attenuates the hemodynamic response (HR) to laryngoscopy and oro-tracheal intubation $(\mathrm{p}<0.001)$. Findings were matched with the studies done by Donald Miller et al ${ }^{28}$ and Helfman SM et al. 8

In our study Lidocaine was ineffective in controlling acute hemodynamic response to laryngoscopy and tracheal intubation. Matches with the findings of Miller C D et al, ${ }^{27} \mathrm{Helfman}$ S M et al , ${ }^{8}$ Feng C.K et al ${ }^{24}$ and Singh et al. ${ }^{9}$

Sympathetic response to laryngoscopy and intubation was seen at $1 \mathrm{~min}$ following intubation in our study in all the three groups. As per our statistical observation with ANOVA (analysis of variance) test, sympathetic response is suppressed in all three groups when considered independently which is statistically significant $(\mathrm{p}<0.001)$. Categorically, clinical parameter (HR) when compared with Chi-square or Fisher exact test, between E-C and E-L, post intubation hemodynamic response was suppressed, which was statistically significant $p<0.001$. In case of $C$ - $L$ comparison, HR was consistently high throughout. This infers neither Clonidine nor Lidocaine is as effective as Esmolol in attenuating HR. 
Similarly for blood pressure response, comparison between E-L and C-L, fall in blood pressure was statistically significant $(\mathrm{p}<0.001)$ between the groups. Inference is that in group L post intubation response suppression was not statistically significant. Whereas in comparison between E$\mathrm{C}$, fall in BP (SBP, DBP and MAP) was not statistically significant. Inference drawn by this observation is that, both the drugs are clinically comparable in reducing the BP.

CONCLUSION: The objective of our study was, to assess the hemodynamic variations to laryngoscopy and intubation and also to evaluate the comparative efficacy among Lidocaine, Esmolol and Clonidine in attenuating the hemodynamic responses.

In conclusion, at $1 \mathrm{~min}$ following intubation, in all the three groups there was significant sympathetic response to laryngoscopy and intubation. We infer from our study, Esmolol $1.5 \mathrm{mg} / \mathrm{kg}$ I.V, 3 min prior to oro-tracheal intubation is a better drug to control HR. Clonidine $1.5 \mu \mathrm{g} / \mathrm{kg} \mathrm{I.V,} 15$ min prior to oro-tracheal intubation is preferred to attenuate hypertensive response to

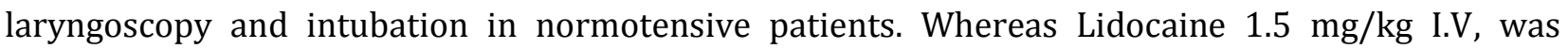
clinically ineffective in attenuating the hemodynamic responses to laryngoscopy and oro-tracheal intubation when compared with I.V Clonidine and I.V Esmolol.

Our study was carried out in normotensive patients. A comparative study between normotensive and optimized hypertensive patients could give a better insight for present day clinical practice, where co-morbidities are seen often in younger generation.

\section{BIBLIOGRAPHY:}

1. King BD, Harris LC, Greifenstein FE, et al. Reflex circulatory response to direct laryngoscopy and tracheal intubation performed during general anaesthesia. Anaesthesiology 1951; 12: 556566.

2. Forbes AM, Dally FG. Acute hypertension during induction of anaesthesia and endotracheal intubation in normotensive man. Br J Anaesth 1970; 42: 618-624.

3. Siedlecki J. Disturbances in the function of cardiovascular system in patient following endotracheal intubation and attempts of their prevention by pharmacological blockade of sympathetic system. Anesth Resus intensive Ther 1975; 3: 107-123.

4. Fleisher LA. Peroperative myocardial ischemia and infarction. Int Anaesthesiol Clin 1994; 4: 115.

5. Gill NP, Wright B, Reilly CS. Relationship between hypoxemia and cardiac ischemic events in the peroperative period. Br JAnaesth 1992; 68: 471-473.

6. Debryshire DR, Fell D, Vaters M. Plasma catecholamine response to tracheal intubation: British Journal of Anaesthesia 1983; 55: 855-9.

7. Bruder $\mathrm{N}$, Ortega $\mathrm{D}$, et al. Consequences and prevention methods of hemodynamic changes during laryngoscopy and intra-tracheal intubation. Ann-Fr-Anasth-Reanim.1992; 11(1): 57-71.

8. Helfman SM, Gold MI, DeLisser EA, Everard A, Herrinton CA. Which drug prevents tachycardia and hypertension associated with tracheal intubation: Lidocaine, fentanyl, esmolol? Anaesth Analg 1991Apr; 72(4): 482-6.

9. Singh H, Viehitvejpaisal P, Gaines GY, White PF. Comparative effects of Lidocaine, Esmolol and Nitroglycerine in modifying the haemodynamic response to laryngoscopy and intubation. J Clin Anaesth 1995 Feb; 7(1): 5-8. 
10. Kumar S, Mishra MN, Mishra LS, Bathla S. Comparative study of the efficacy of i.v. Esmolol, Diltiazem and Magnesium sulphate in attenuating haemodynamic response to laryngoscopy and tracheal intubation. Indian J Anaesth 2003; 47(1): 41-4.

11. Marco P. Zalunardo, Andreas Zollinger, Donat R. Spahn, Burkhardt Seifert, Thomas Pasch. Preoperative Clonidine attenuates stress response during emergence from anesthesia. Clin J Anaesth. 2000 Aug; 12(5): 343- 419.

12. IditMatot, Sichel JY, Valeri Yofe, Yaacov Gozal, The Effect of Clonidine Premedication on Hemodynamic Responses to Microlaryngoscopy and Rigid Bronchoscopy. Anaesth Analg. 2000 Oct; 91(4): 828-833.

13. Tomori Z, Widdicombe JG. Muscular, bronchomotor and cardiovascular reflexes elicited by mechanical stimulation of the respiratory tract. J Physiol 1969; 200: 25-49.

14. Splinter WM, Cervenko F. Hemodynamic responses to laryngoscopy and tracheal intubation in geriatric patients: effects of fentanyl, lidocaine and thiopentone. Can J Anaesth 1989; 36(4): 370-6.

15. Ismail S, Azam SI, Khan FA. Effect of age on hemodynamic response to tracheal intubation: A comparison of young middle age and elderly patients. Anaesth Intensive Care 2002; 30(5): 608-14.

16. Singh S, Smith JE. Cardiovascular changes after three stages of nasotracheal intubation.Br J Anaesth. 2003; 91: 667-71.

17. Nandita S, Kodadia MM, Geeta A. Cardiovascular changes during diagnostic laryngoscopy under general anaesthesia. Ind J Anaesth 1988; 36(5): 270.

18. Bucx MJL, Van Geel RTM, Scheck PAE and Stijnen T. Cardiovascular effects of force applied during laryngoscopy. Anaesthesia 1995; 50: 17-22.

19. Bachofen M. Suppression of blood pressure increase during intubation: Lidocaine or Fentanyl. Anaesthesia 1988; 37(3): 156-61.

20. Zalunardo P, Andreas Zollinger, Donat R. Spahn, Burkhardt Seifert, Mahmoud Radjaipour, Kurt Gautschi and Thomas Pasch. Effects of intravenous and oral Clonidine on hemodynamic and plasma-catecholamine response due to endotracheal intubation. J Clin Anesth 1997 March; 9 (2): 143-147.

21. Laurito CX. Baughman, Becker, Cunningham F, Pygon BH. Oral Clonidine blunts the hemodynamic responses to brief but not prolonged laryngoscopy. JClinAnaesth.1993; 5: 54-7.

22. James F. Hamill, Robert Bedford F, David CW, Austin RC. Lidocaine before endotracheal intubation: intravenous or laryngotracheal? Anaesthesiology 1981; 55: 578-581.

23. Stanley Tam, Frances Chung, Michael Campbell. Intravenous lignocaine; optimal time for injection before tracheal intubation. Anaesth Analg 1987; 66: 1036-1038.

24. Feng CK, Chan KH, Liu KN. A comparison of lidocaine, Fentanyl and Esmolol for attenuation of cardiovascular response to laryngoscopy and tracheal intubation. Acta Anaesthesiol Sin 1996 Sep; 34(3): 172.

25. Adachi YU, Satomoto M, Higuchi H, Watanabe K. Clonidine attenuates the hemodynamic response to endotracheal intubation more than the response to laryngoscopy. Anaesth Analg 2002 Jul; 95(1): 233-7.

26. Kobayashi TL, Watanabe K, Ito T. Lack of effect of i.v. lidocaine on cardiovascular responses to laryngoscopy and intubation. Masui 1995; 44: 579-82. 
27. Miller CD, Warren SJ. Lignocaine fails to attenuate the cardiovascular responses to laryngoscopy and intubation. Br J Anaesth 1990; 65: 216-219.

28. Donald R. Miller, Raymond J. Martineau, Wynands JE and Jeremy Hill. Bolus administration of esmolol for controlling the haemodynamic response to tracheal intubation: the Canadian multicentre trial Can J Anesth 1991; 38(7): 849-858.

\begin{tabular}{|l|c|c|c|}
\hline & Group E & Group C & Group L \\
\hline Sex M/F & $19 / 16$ & $19 / 16$ & $22 / 13$ \\
\hline Age (years) & $45.63 \pm 11.07$ & $50.77 \pm 11.87$ & $49.57 \pm 11.92$ \\
\hline Weight (kg) & $59.51 \pm 9.77$ & $61.57 \pm 9.41$ & $60.97 \pm 9.67$ \\
\hline \multicolumn{4}{|c|}{ Table 1: Patients data } \\
\hline
\end{tabular}

\begin{tabular}{|c|c|c|c|c|c|c|c|c|c|c|}
\hline \multirow{3}{*}{$\begin{array}{c}\text { Heart rate } \\
\text { Baseline }\end{array}$} & \multirow{2}{*}{\multicolumn{2}{|c|}{$\begin{array}{c}\text { Group E } \\
\text { Mean } \pm \text { SD \& \% }\end{array}$}} & \multirow{2}{*}{\multicolumn{2}{|c|}{$\begin{array}{c}\text { Group C } \\
\text { Mean } \pm \text { SD \& \% }\end{array}$}} & \multirow{2}{*}{\multicolumn{2}{|c|}{$\begin{array}{c}\text { Group L } \\
\text { Mean } \pm \text { SD \& \% }\end{array}$}} & \multirow{3}{*}{$\begin{array}{c}\begin{array}{c}\text { Overall } \\
\text { p value }\end{array} \\
0.129\end{array}$} & \multicolumn{3}{|c|}{ Significance } \\
\hline & & & & & & & & \multirow{2}{*}{$\begin{array}{c}\mathbf{E}-\mathbf{C} \\
0.161\end{array}$} & \multirow{2}{*}{$\begin{array}{c}\text { E-L } \\
0.987\end{array}$} & \multirow{2}{*}{$\begin{array}{c}\text { C-L } \\
0.214\end{array}$} \\
\hline & $86.69 \pm 3.71$ & - & $88.40 \pm 3.34$ & - & $86.82 \pm 4.53$ & - & & & & \\
\hline After Induction & $87.09 \pm 5.10$ & 0.72 & $88.17 \pm 3.34$ & -0.20 & $87.69 \pm 4.73$ & 1.18 & 0.595 & 0.566 & 0.840 & 0.892 \\
\hline $0 \mathrm{~min}$ & $89.60 \pm 3.22$ & 3.44 & $100.46 \pm 5.11$ & 13.72 & $101.63 \pm 3.16$ & 17.32 & $<0.001^{* *}$ & $<0.001^{* *}$ & $<0.001^{* *}$ & 0.430 \\
\hline $1 \mathrm{~min}$ & $90.80 \pm 2.86$ & 4.85 & $101.49 \pm 4.67$ & 14.91 & $102.11 \pm 2.68$ & 17.90 & $<0.001^{* *}$ & $<0.001^{* *}$ & $<0.001^{* *}$ & 0.736 \\
\hline $2 \mathrm{~min}$ & $88.26 \pm 2.87$ & 1.88 & $99.23 \pm 5.76$ & 12.33 & $99.91 \pm 3.44$ & 15.35 & $<0.001^{* *}$ & $<0.001^{* *}$ & $<0.001^{* *}$ & 0.735 \\
\hline $3 \mathrm{~min}$ & $87.31 \pm 2.86$ & 0.79 & $98.66 \pm 5.77$ & 11.68 & $98.91 \pm 3.50$ & 14.19 & $<0.001^{* *}$ & $<0.001^{* *}$ & $<0.001^{* *}$ & 0.965 \\
\hline $4 \mathrm{~min}$ & $86.63 \pm 2.87$ & 0.00 & $97.40 \pm 5.59$ & 10.25 & $97.26 \pm 3.19$ & 12.28 & $<0.001^{* *}$ & $<0.001^{* *}$ & $<0.001^{* *}$ & 0.988 \\
\hline $6 \mathrm{~min}$ & $85.66 \pm 3.61$ & -1.10 & $94.29 \pm 5.4$ & 6.75 & $93.97 \pm 3.52$ & 8.45 & $<0.001^{* *}$ & $<0.001^{* *}$ & $<0.001^{* *}$ & 0.949 \\
\hline $8 \min$ & $84.77 \pm 3.32$ & -2.12 & $91.17 \pm 5.25$ & 3.24 & $85.23 \pm 20.64$ & -1.49 & $0.061+$ & $0.085+$ & 0.987 & 0.118 \\
\hline $10 \mathrm{~min}$ & $84.17 \pm 3.22$ & -2.80 & $88.00 \pm 4.71$ & -0.35 & $88.34 \pm 8.57$ & 1.88 & $0.006^{* *}$ & $0.022^{*}$ & $0.011^{*}$ & 0.968 \\
\hline
\end{tabular}

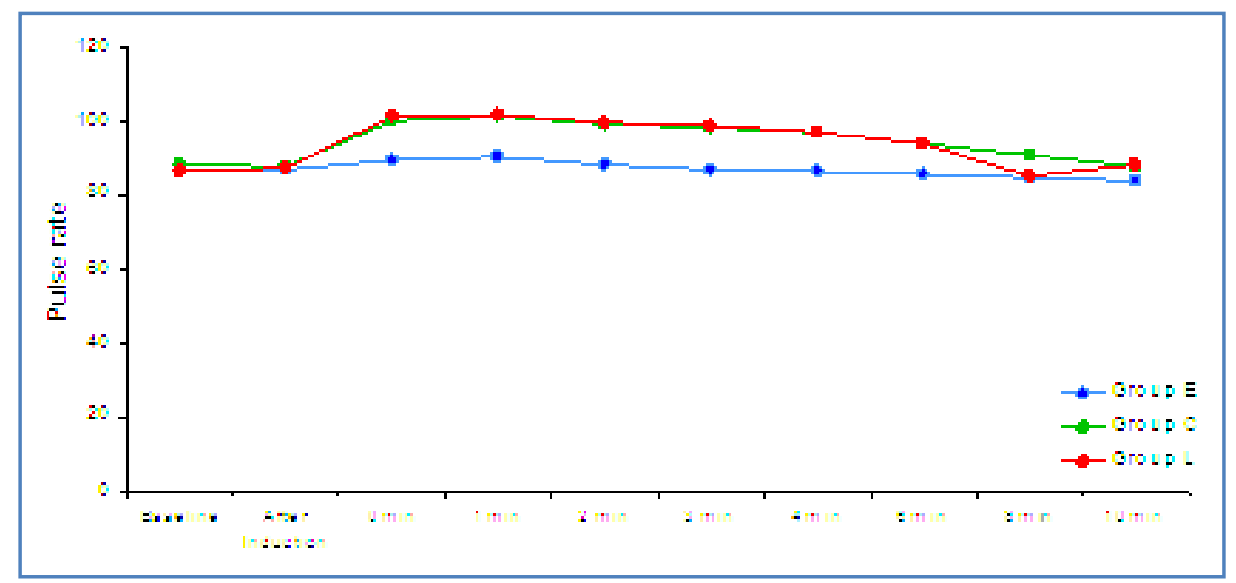

Figure. 1 


\begin{tabular}{|c|c|c|c|c|c|c|c|c|c|c|}
\hline \multirow{3}{*}{$\begin{array}{c}\begin{array}{c}\text { SBP } \\
\text { (mmHg) }\end{array} \\
\text { Baseline }\end{array}$} & \multirow{2}{*}{\multicolumn{2}{|c|}{$\begin{array}{c}\text { Group E } \\
\text { Mean } \pm \text { SD \& \% }\end{array}$}} & \multirow{2}{*}{\multicolumn{2}{|c|}{$\begin{array}{c}\text { Group C } \\
\text { Mean } \pm \text { SD \& \% }\end{array}$}} & \multirow{2}{*}{\multicolumn{2}{|c|}{$\begin{array}{c}\text { Group L } \\
\text { Mean } \pm \text { SD \& \% }\end{array}$}} & \multirow{3}{*}{$\begin{array}{c}\text { p value } \\
0.132\end{array}$} & \multicolumn{3}{|c|}{ Significance } \\
\hline & & & & & & & & E-C & E-L & C-L \\
\hline & $126.97 \pm 4.01$ & - & $130.17 \pm 20.7$ & - & $133.09 \pm 5.54$ & - & & 0.539 & 0.110 & 0.598 \\
\hline $\begin{array}{c}\text { After } \\
\text { Induction }\end{array}$ & $107.46 \pm 8.13$ & -15.36 & $120.34 \pm 18.56$ & -6.94 & $124.69 \pm 7.79$ & -6.13 & $<0.001^{* *}$ & $<0.001^{* *}$ & $<0.001^{* *}$ & 0.320 \\
\hline 0 min & $138.43 \pm 7.96$ & 9.09 & $139.31 \pm 5.55$ & 29.96 & $161.43 \pm 7.04$ & 21.45 & $<0.001^{* *}$ & 0.854 & $<0.001^{* *}$ & $<0.001^{* *}$ \\
\hline $1 \mathrm{~min}$ & $139.11 \pm 7.43$ & 9.63 & $138.86 \pm 5.75$ & 29.61 & $162.63 \pm 7.56$ & 22.31 & $<0.001^{* *}$ & 0.987 & $<0.001^{* *}$ & $<0.001^{* *}$ \\
\hline $2 \min$ & $128.69 \pm 6.54$ & 1.41 & $130.57 \pm 5.26$ & 21.58 & $152.8 \pm 7.85$ & 14.94 & $<0.001^{* *}$ & 0.463 & $<0.001^{* *}$ & $<0.001^{* *}$ \\
\hline $3 \min$ & $127.6 \pm 5.98$ & 0.57 & $128.86 \pm 5.43$ & 19.93 & $147.37 \pm 7.08$ & 10.86 & $<0.001^{* *}$ & 0.674 & $<0.001^{* *}$ & $<0.001^{* *}$ \\
\hline $4 \min$ & $121.03 \pm 6.48$ & -4.64 & $124.46 \pm 19.55$ & 15.64 & $140.51 \pm 7.02$ & 5.68 & $<0.001^{* *}$ & $<0.001^{* *}$ & $<0.001^{* *}$ & $<0.001^{* *}$ \\
\hline $6 \mathrm{~min}$ & $118.06 \pm 7.75$ & -6.98 & $125.60 \pm 4.44$ & 16.43 & $136.37 \pm 6.19$ & 2.58 & $<0.001^{* *}$ & $<0.001^{* *}$ & $<0.001^{* *}$ & $<0.001^{* *}$ \\
\hline $8 \mathrm{~min}$ & $115.09 \pm 7.57$ & -9.34 & $124.40 \pm 3.96$ & 15.16 & $132.57 \pm 5.85$ & -0.27 & $<0.001^{* *}$ & $<0.001^{* *}$ & $<0.001^{* *}$ & $<0.001^{* *}$ \\
\hline $10 \mathrm{~min}$ & $113.43 \pm 6.71$ & -10.64 & $123.71 \pm 3.92$ & 14.63 & $128.34 \pm 8.68$ & -3.53 & $<0.001^{* *}$ & $<0.001^{* *}$ & $<0.001^{* *}$ & $<0.001^{* *}$ \\
\hline
\end{tabular}

\begin{tabular}{|c|c|c|c|c|c|c|c|c|c|c|}
\hline \multirow{3}{*}{$\begin{array}{c}\begin{array}{c}\text { DBP } \\
\text { (mmHg) }\end{array} \\
\text { Baseline }\end{array}$} & \multirow{2}{*}{\multicolumn{2}{|c|}{$\begin{array}{c}\text { Group E } \\
\text { Mean } \pm S D ~ \& ~ \% ~\end{array}$}} & \multirow{2}{*}{\multicolumn{2}{|c|}{$\begin{array}{c}\text { Group C } \\
\text { Mean } \pm \text { SD \& \% }\end{array}$}} & \multirow{2}{*}{\multicolumn{2}{|c|}{$\begin{array}{c}\text { Group L } \\
\text { Mean } \pm \text { SD \& \% }\end{array}$}} & \multirow{3}{*}{$\begin{array}{c}\text { p value } \\
0.303\end{array}$} & \multicolumn{3}{|c|}{ Significance } \\
\hline & & & & & & & & E-C & E-L & C-L \\
\hline & $82.62 \pm 5.13$ & - & $83.31 \pm 4.09$ & - & $84.23 \pm 3.59$ & - & & 0.785 & 0.272 & 0.651 \\
\hline $\begin{array}{c}\text { After } \\
\text { Induction }\end{array}$ & $69.57 \pm 6.41$ & -15.71 & $70.91 \pm 6.66$ & -14.81 & $80.51 \pm 5.10$ & -4.35 & $<0.001^{* *}$ & 0.628 & $<0.001^{* *}$ & $<0.001^{* *}$ \\
\hline $0 \mathrm{~min}$ & $90.63 \pm 14.37$ & 9.91 & $88.00 \pm 6.17$ & 5.80 & $95.43 \pm 3.84$ & 13.53 & $0.004^{* *}$ & 0.466 & $0.083+$ & $0.003^{* *}$ \\
\hline $1 \mathrm{~min}$ & $91.80 \pm 12.74$ & 11.60 & $89.89 \pm 4.85$ & 8.07 & $98.11 \pm 3.18$ & 16.67 & $<0.001^{* *}$ & 0.584 & $0.004^{* *}$ & $<0.001^{* *}$ \\
\hline $2 \min$ & $86.80 \pm 7.35$ & 5.25 & $85.49 \pm 5.60$ & 2.72 & $92.74 \pm 4.15$ & 10.35 & $<0.001^{* *}$ & 0.616 & $<0.001^{* *}$ & $<0.001^{* *}$ \\
\hline $3 \mathrm{~min}$ & $85.20 \pm 6.00$ & 3.30 & $81.71 \pm 5.96$ & -1.81 & $91.03 \pm 4.27$ & 8.29 & $<0.001^{* *}$ & $0.024^{*}$ & $<0.001^{* *}$ & $<0.001^{* *}$ \\
\hline $4 \min$ & $80.11 \pm 4.90$ & -2.87 & $81.03 \pm 5.14$ & -2.63 & $88.91 \pm 3.77$ & 5.77 & $<0.001^{* *}$ & 0.689 & $<0.001^{* *}$ & $<0.001^{* *}$ \\
\hline $6 \mathrm{~min}$ & $77.40 \pm 13.23$ & -6.09 & $79.37 \pm 4.44$ & -4.61 & $86.57 \pm 3.48$ & 2.97 & $<0.001^{* *}$ & 0.583 & $<0.001^{* *}$ & $<0.001^{* *}$ \\
\hline $8 \mathrm{~min}$ & $75.37 \pm 5.31$ & -8.66 & $77.26 \pm 3.36$ & -7.09 & $83.20 \pm 3.47$ & -1.03 & $<0.001^{* *}$ & 0.143 & $<0.001^{* *}$ & $<0.001^{* *}$ \\
\hline $10 \mathrm{~min}$ & $74.29 \pm 5.09$ & -9.93 & $76.91 \pm 2.49$ & -7.49 & $80.71 \pm 5.54$ & -4.04 & $<0.001^{* *}$ & $0.047^{*}$ & $<0.001^{* *}$ & $<0.001^{* *}$ \\
\hline
\end{tabular}




\section{ORIGINAL ARTICLE}

\begin{tabular}{|c|c|c|c|c|c|c|c|c|c|c|}
\hline \multirow{3}{*}{$\begin{array}{c}\text { MAP (mmHg) } \\
\text { Baseline }\end{array}$} & \multirow{2}{*}{\multicolumn{2}{|c|}{$\begin{array}{c}\text { Group E } \\
\text { Mean } \pm \text { SD \& \% }\end{array}$}} & \multirow{2}{*}{\multicolumn{2}{|c|}{$\begin{array}{c}\text { Group C } \\
\text { Mean } \pm \text { SD \& \% }\end{array}$}} & \multirow{2}{*}{\multicolumn{2}{|c|}{$\begin{array}{c}\text { Group L } \\
\text { Mean } \pm \text { SD \& \% }\end{array}$}} & \multirow{3}{*}{$\begin{array}{c}\text { p value } \\
0.492\end{array}$} & \multicolumn{3}{|c|}{ Significance } \\
\hline & & & & & & & & E-C & E-L & C-L \\
\hline & $99.55 \pm 4.81$ & - & $100.65 \pm 2.85$ & - & $100.19 \pm 3.74$ & - & & 0.462 & 0.768 & 0.873 \\
\hline After Induction & $82.62 \pm 6.98$ & -16.98 & $88.53 \pm 15.93$ & -12.03 & $95.67 \pm 4.50$ & -4.37 & $<0.001^{* *}$ & $0.050^{*}$ & $<0.001^{* *}$ & $0.013^{*}$ \\
\hline $0 \mathrm{~min}$ & $107.13 \pm 10.74$ & 7.80 & $104.54 \pm 5.44$ & 3.88 & $117.27 \pm 6.45$ & 17.06 & $0.004^{* *}$ & 0.356 & $<0.001^{* *}$ & $<0.001^{* *}$ \\
\hline $1 \mathrm{~min}$ & $107.44 \pm 9.25$ & 8.17 & $105.54 \pm 4.89$ & 4.88 & $118.66 \pm 4.76$ & 18.49 & $<0.001^{* *}$ & 0.458 & $<0.001^{* *}$ & $<0.001^{* *}$ \\
\hline $2 \min$ & $100.77 \pm 5.46$ & 1.37 & $101.84 \pm 3.92$ & 1.23 & $113.06 \pm 3.49$ & 12.96 & $<0.001^{* *}$ & 0.564 & $<0.001^{* *}$ & $<0.001^{* *}$ \\
\hline $3 \mathrm{~min}$ & $99.11 \pm 4.41$ & -0.28 & $98.33 \pm 3.94$ & -2.25 & $110.19 \pm 3.74$ & 10.09 & $<0.001^{* *}$ & 0.699 & $<0.001^{* *}$ & $<0.001^{* *}$ \\
\hline 4 min & $93.87 \pm 4.28$ & -5.56 & $96.12 \pm 4.15$ & -4.44 & $107.49 \pm 3.99$ & 7.37 & $<0.001^{* *}$ & $0.064+$ & $<0.001^{* *}$ & $<0.001^{* *}$ \\
\hline $6 \mathrm{~min}$ & $92.36 \pm 4.88$ & -7.04 & $95.63 \pm 3.60$ & -4.92 & $103.33 \pm 3.07$ & 3.24 & $<0.001^{* *}$ & $<0.001^{* *}$ & $<0.001^{* *}$ & $<0.001^{* *}$ \\
\hline $8 \mathrm{~min}$ & $88.98 \pm 5.26$ & -10.44 & $93.46 \pm 3.61$ & -7.08 & $99.84 \pm 2.81$ & -0.24 & $<0.001^{* *}$ & $<0.001^{* *}$ & $<0.001^{* *}$ & $<0.001^{* *}$ \\
\hline 10 min & $87.67 \pm 5.21$ & -11.74 & $92.87 \pm 3.18$ & -7.66 & $96.79 \pm 3.81$ & -3.33 & $<0.001^{* *}$ & $<0.001^{* *}$ & $<0.001^{* *}$ & $<0.001^{* *}$ \\
\hline
\end{tabular}

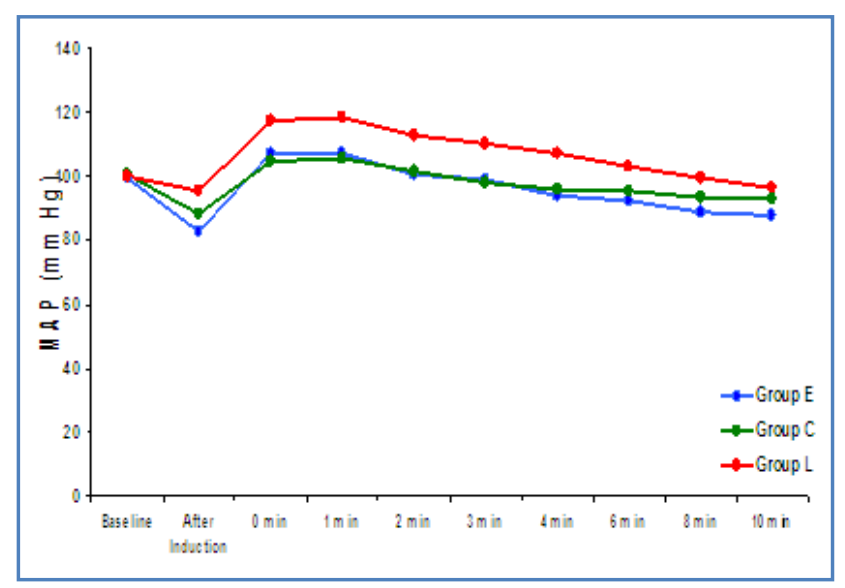

\section{Figure. 2}

\section{AUTHORS:}

1. Savitha K.S.

2. Sampa Anupurba

3. Smita L. Almeida

\section{PARTICULARS OF CONTRIBUTORS:}

1. Associate Professor, Department of Anaesthesia, St. John's Medical College Hospital, Bangalore, Karnataka, India.

2. Senior Registrar, Apollo Hospitals, Bhubaneswar, Odessa, India.

3. Assistant Professor, Department of Anaesthesia, St. John's Medical College Hospital, Bangalore, Karnataka, India.

\author{
NAME ADDRESS EMAIL ID OF THE \\ CORRESPONDING AUTHOR: \\ Dr. Savitha K.S., \\ $1020,25^{\text {th }}$ Main, 38 ${ }^{\text {th }}$ Cross, \\ $4^{\text {th }}$ ' $\mathrm{T}$ ' Block, Jayanagar, \\ Bangalore - 560041, \\ Karnataka, India. \\ Email-drsavitha_ks@yahoo.com
}

Date of Submission: 21/12/2013.

Date of Peer Review: 23/12/2013.

Date of Acceptance: 04/01/2014.

Date of Publishing: 10/01/2014 